\title{
Preface for the article collection "Land-Ocean Linkages under the Influence of the Asian Monsoon"
}

\author{
Ryuji Tada ${ }^{1 *}$ and Richard W. Murray ${ }^{2}$
}

Keywords: Land-ocean linkage, Asian monsoon, East Asian marginal seas, Kuroshio, Tsushima Warm Current, Yangtze River, Volcanic ash, IODP

\section{Preface}

Land-ocean interactions are an essential part of the climatic system, and monsoons are perhaps the most important example of such interactions. The Asian monsoon is by far the largest monsoon system on the globe, and its impact is felt worldwide. This monsoon system influences the lives of more than one half of the world's population via the hydrological cycle and its variability over time. The Asian monsoon also exerts a significant impact on the condition of the oceans surrounding Asia through freshwater discharge, nutrient inputs, and strong winds. Such impacts are especially significant in marginal seas because of their high sensitivity to climate change. We hope that the articles collected in this issue in the Special Call for Excellent Papers on Hot Topics (SPEPS) series will stimulate and promote future research on land-ocean linkages in Asia and their relationship with the Asian monsoon.

The eastern margin of Asia is unique because of the large number of marginal seas that were formed as a result of the collision between India and Eurasia that began at ca. $45 \mathrm{Ma}$. The collision also caused the uplift of the Himalaya and Tibet, which is considered to be one of the main causes of the establishment and intensification of the Asian monsoon during the Cenozoic. Consequently, it is worthwhile exploring (1) how the Asian monsoon was established and then evolved through time; (2) what kinds of land-ocean interactions the Asian monsoon has caused throughout the marginal

\footnotetext{
* Correspondence: ryuji@eps.s.u-tokyo.ac.jp

${ }^{1}$ Department of Earth and Planetary Science, Graduate School of Science, The University of Tokyo, 7-3-1 Hongo, Bunkyo-ku, Tokyo 113-0033, Japan Full list of author information is available at the end of the article
}

sea regions; and (3) how the Asian monsoon has affected the oceanography of the marginal seas.

Scientific ocean drilling has contributed to society's understanding of monsoonal systems for decades. Most recently, a focused series of the Integrated Ocean Drilling Program and International Ocean Discovery Program (IODP) expeditions conducted drilling campaigns from 2013 to 2016 that targeted the Asian monsoon and its possible linkage with the uplift of the Himalaya and Tibet (Fig. 1). Thus, considerable advances in our understanding of monsoonal processes are expected over the coming years. Consequently, it seems worthwhile to summarize the present status of our knowledge on this theme and identify the major problems that remain to be solved.

Soon after IODP Expedition 346 (named "Asian Monsoon") was completed in 2013, a special session entitled "Land-Ocean Linkages in East Asian Marginal Seas" was held on April 29, 2014, during the Japan Geoscience Union (JpGU) annual meeting in Yokohama (Fig. 2). Twelve oral and four poster presentations were given at the special JpGU session, and the papers presented in this issue include three research articles and six reviews based on presentations from that session. These nine papers cover the evolution and variability of the Asian monsoon (Tada et al. 2016), the evolution of surface water and deep-water circulation in East Asian marginal seas (Gallagher et al. 2015; Kim et al. 2015; Itaki 2016), the impact of the East Asian summer monsoon on the composition of sediment discharged from the Yangtze River, surface water salinity in the East China Sea, flood records and typhoon tracks in southern Japan (He et al. 2015; Horikawa et al. 2015; Suzuki et al. 2016), and volcanic ash as a useful tool for land-ocean correlation and as a 


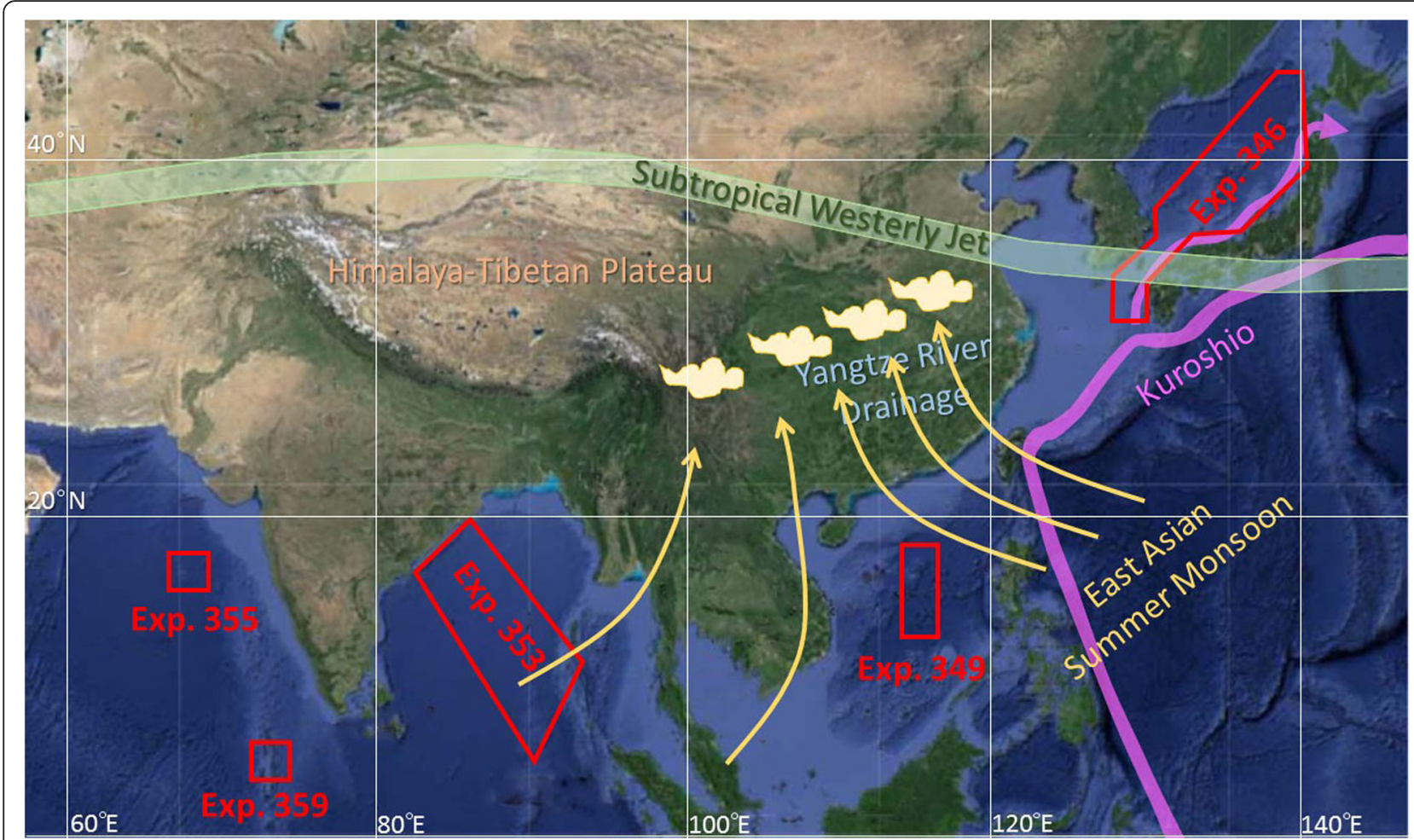

Fig. 1 Expedition areas of the IODP drilling campaigns between 2013 and 2016 targeting the Asian monsoon. Map image: 2016 TerraMetrics

significant source of sedimentary material in the northwest Pacific Ocean (Ikehara 2015; Scudder et al. 2016).

When and how the Asian monsoon system developed, and how it has evolved, are long-standing questions in paleoclimatic and earth system sciences. The uplift of the
Himalaya and Tibet played a critical role in the establishment of the Asian monsoon and its evolution through time. Tada et al. (2016) synthesize recent progress made by studies related to this linkage from the viewpoints of paleoclimatic modeling, Himalaya-Tibet tectonics, and

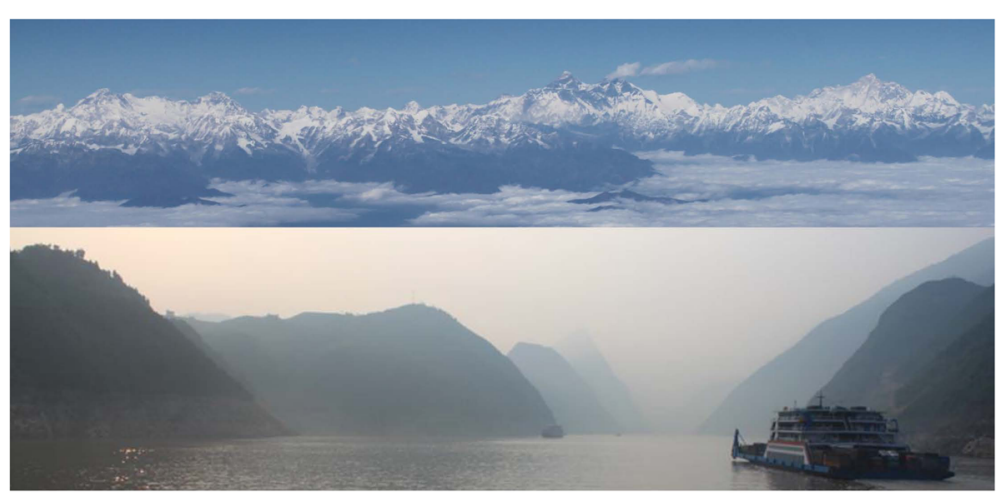

Land-Ocean Linkages under the influence of Asian Monsoon

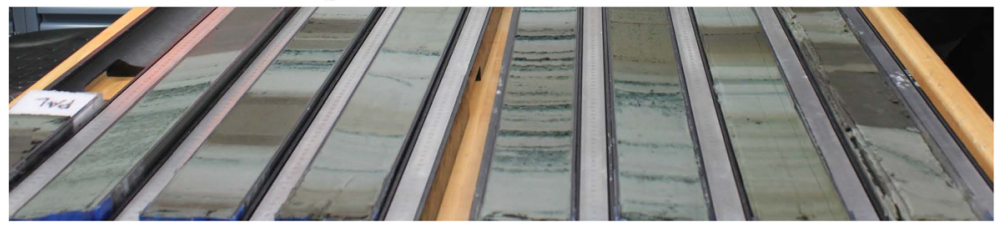

Fig. 2 Poster used for the Special Call for Excellent Papers on Hot Topics: "Land-Ocean Linkages under the Influence of the Asian Monsoon". From top to bottom: the Himalaya Mountains, the Yangtze River, and a Quaternary sediment core from the Sea of Japan 
paleoclimatic and paleoceanographical proxy studies of the Asian monsoon. They found probable linkages between tectonics and climate that are conformable with model predictions, suggesting that the Himalaya-Tibet uplift played a critical role, not only in the establishment of the Asian monsoon but also in global cooling during the Cenozoic. Thus, Tada et al.'s (2016) review provides the general background to this issue.

The Kuroshio Current, a western boundary current in the North Pacific, exerts a significant impact on the climate of East Asia and its marginal seas. Originating in the equatorial western Pacific, the Kuroshio flows northwards along the Philippine archipelago and flows into the East China Sea through the East Taiwan Channel and out at its northern end via the Tokara Strait. The Kuroshio Current flows farther northeastward along the Japanese Islands until it reaches about $35^{\circ} \mathrm{N}$, where it is deflected to the east to form the Kuroshio Extension. In the northern part of the East China Sea, part of the Kuroshio branches to form the Tsushima Warm Current (TWC) that flows into the Japan Sea and supplies heat, freshwater, and nutrients. Consequently, the climate on the Japan Sea side of the Japanese Islands is influenced by the nature and intensity of the TWC. However, the pathway and intensity of the Kuroshio Current, and subsequently the TWC, are expected to have been different during glacial periods when global sea level was lowered by as much as $130 \mathrm{~m}$ and also during the Pliocene, when the Okinawa Trough was closed, resulting in restricted circulation.

Using various proxies for the behavior of the Kuroshio Current and TWC, Gallagher et al. (2015) summarize the evolution of the Kuroshio Current during the PlioPleistocene. Itaki (2016) reviews changes in microfossil assemblages in the Japan Sea during the late Pliocene to early Pleistocene to reconstruct changes in the connectivity to the northwestern Pacific Ocean and the East China Sea, as well as the possible impact of the East Asian winter monsoon on deep-water ventilation. These two reviews provide important information on the evolution and variability of the Kuroshio Current and the TWC and their relationship with regional tectonics, as well as their interaction with the East Asian monsoon.

Sea surface temperature (SST) in the Okinawa Trough in the East China Sea is commonly used as an indicator of Kuroshio intrusion. SST in the northern part of the Okinawa Trough is also influenced by discharge from rivers in south China (Kubota et al. 2010). Previous studies used various SST proxies to investigate the intensity and path of the Kuroshio Current, as well as the influence of river discharge from south China. However, past SSTs estimated from various proxies do not necessarily yield consistent outcomes, and some interpretations of the past behavior of the Kuroshio Current have been controversial. Kim et al. (2015) review modern SST estimation using various proxies to determine which proxies are the most reliable for which seasons. They then review SST reconstruction during the last glacial period to address the ongoing controversy over whether the Kuroshio intruded into the Okinawa Trough during the last glacial maximum. This issue is closely related to the discussion regarding whether the TWC existed during glacial periods.

The nature of the TWC is influenced not only by the Kuroshio Current but also by the relative contribution of the East China Sea Coastal Water, which is influenced by discharge from the Yangtze River (Tada et al. 1999). As the Yangtze discharge reflects the intensity of summer monsoon precipitation over south China, sea surface salinity (SSS) in the northern East China Sea could be a good measure of the intensity of the East Asian summer monsoon (Kubota et al. 2010), that is, when summer monsoon precipitation increases (decreases) over south China, the Yangtze discharge also increases (decreases), causing SSS in the East China Sea to decrease (increase). As past SSS is estimated from the oxygen isotope ratio of surface water, which decreases with decreasing SSS, it is necessary to understand the relationship between the oxygen isotope ratio of surface water and SSS in the East China Sea. As such, based on extensive sampling and analysis of surface waters of the East China Sea, Horikawa et al. (2015) derive a new equation that describes the relationship between SSS and the oxygen isotope ratio of surface water during summer. They also evaluate equations previously used to estimate the oxygen isotope ratio of surface water from the $\mathrm{Mg} / \mathrm{Ca}$ and oxygen isotope ratios of planktonic foraminifera in this region. Their study provides an enhanced and sound basis from which to estimate East Asian summer monsoon intensity and its changes in the past using SSS reconstructions from the northern East China Sea.

The chemical composition of fine-grained sediments at continental margins provides useful information on sediment source(s) and/or climate and tectonic settings in the source area. Sediment provenance is a reliable tracer of river discharge, and the Yangtze River is the major source of freshwater entering the northern East China Sea. Therefore, understanding the chemical characteristics of the sediments discharged from the Yangtze River and their controlling factors can provide important insights into the climate of the Asian interior, as well as the source regions of the sediments deposited in the marginal sea. He et al. (2015) synthesize the results of extensive sampling and analysis of sediments collected from throughout the main stream of the Yangtze River, as well as its major tributaries, to characterize the fine-grained sediment discharged from the Yangtze and evaluate the effect of chemical weathering on its composition. Their findings provide useful constraints that can be used to evaluate the contribution of the fine-grained sediment discharged by the Yangtze River to the sediments deposited in the East China Sea. 
Floods are one of the major processes contributing to sediment discharge from land to ocean. However, there are few proxies available that are able to quantitatively record flood events. Annually laminated lake sediments provide a rare opportunity to visualize sediment layers deposited by floods and to compare the age and thickness of flood layers with the timing and magnitude of heavy precipitation events in the observational record. Suzuki et al. (2016) conducted such a study using sediment cores recovered from Lake Suigetsu that record the history of the last $\sim 370$ years. Their results are promising because the sediments record flood events that were caused mostly by typhoons and their work demonstrates that the thickness of a given flood layer faithfully records the magnitude of heavy precipitation.

The East Asian marginal seas are bounded by volcanic arcs on their eastern sides, and these provide considerable amounts of volcanic material to the marginal seas and western Pacific region. This volcanic ash, in addition to being indicative of volcanism and tectonism through time, is an extremely powerful tool that facilitates highprecision correlation between land and ocean, within and among the marginal seas, and also between the marginal seas and the northwestern Pacific Ocean. Basic data on the chemical composition and stratigraphic position of volcanic ash layers (tephras) surrounding Japan are relatively abundant. Ikehara (2015) presents a tephrochronology for Japan and surrounding seas and demonstrates its utility from various aspects. The data presented provide an important approach that can be used to refine the existing regional chronostratigraphy and will serve as a new tool for various aspects of paleoclimatic and paleoceanographical research.

It is easy to identify volcanic ash when it occurs as discrete layers; however, when the ash grains are dispersed (i.e., mixed through the bulk sediment), it is difficult to recognize them. Consequently, the contribution of volcanic ash to pelagic sediments in open oceans, as well as to hemipelagic sediments in marginal areas, is uncertain and probably significantly underestimated. Scudder et al. (2016) summarize the geochemical and statistical techniques that can be used to determine the composition of dispersed ashes and quantify their contribution to such ocean sediments. Combined with the results provided by $\mathrm{He}$ et al. (2015), their method is particularly useful for evaluating the origins and relative contributions of finegrained siliciclastic sediments to the hemipelagic sediments of the East China and Japan seas.

The papers in this issue represent an impressive amount of research that was completed over a relatively short period of time. Moving forward, future studies of the Asian monsoon will surely benefit from the discussions presented here. Integrating these results with the ongoing studies from Expedition 346, as well as with the other recent IODP expeditions to other monsoon regions (e.g., Expedition 353, Bengal), is likely to lead to a new level of understanding of the interrelationships between land and ocean. As climate continues to change, and population demographics shift, understanding these systems will become of even greater importance to society and decision-makers.

\section{Abbreviations}

IODP, Integrated Ocean Drilling Program and following International Ocean Discovery Program; JpGU, Japan Geoscience Union; SPEPS, Special Call for Excellent Papers on Hot Topics; SSS, sea surface salinity; SST, sea surface temperature; TWC, Tsushima Warm Current

\section{Acknowledgements}

This special issue is based on a special session entitled "Land-Ocean Linkages in East Asian Marginal Seas" held on April 29, 2014, at the Japan Geoscience Union (JpGU) annual meeting in Yokohama. The session consisted of 12 oral and 4 poster presentations and included 4 presentations from outside Japan. The session was highly successful, with energetic discussions, and resulted in nine papers being submitted to this special issue. Travel expenses of the speakers from outside Japan were supported by JpGU, and we thank the PEPS staff for the logistical help provided to the foreign participants. We thank Drs. Ken Ikehara of the Geological Survey of Japan and Andrew Henderson of Newcastle University for serving as Associate Editors. We also thank the PEPS staff for their support during the submission and revision of the manuscripts and the PEPS editorial board for the helpful and swift editorial handling of the manuscripts. Portions of RWM's time working as Editor were supported while RWM was serving at the US National Science Foundation.

\section{Authors' contributions}

RT wrote the draft of this manuscript, and RWM rewrote and confirmed the contents. Both authors read and approved the final manuscript.

\section{Competing interests}

The authors declare that they have no competing interests.

\section{Author details}

'Department of Earth and Planetary Science, Graduate School of Science, The University of Tokyo, 7-3-1 Hongo, Bunkyo-ku, Tokyo 113-0033, Japan. ${ }^{2}$ Department of Earth \& Environment, Boston University, Boston, MA 02215, USA.

Received: 4 August 2016 Accepted: 4 August 2016

Published online: 22 August 2016

\section{References}

Gallagher SJ, Kitamura A, Iryu Y, Itaki T, Koizumi I, Hoiles PW (2015) The Pliocene to recent history of the Kuroshio and Tsushima Currents: a multi-proxy approach. Prog Earth Planet Sci 2:17. doi:10.1186/s40645-015-0045-6

He M, Zheng H, Clift PD, Tada R, Wu W, Luo C (2015) Geochemistry of finegrained sediments in the Yangtze River and the implications for provenance and chemical weathering in East Asia. Prog Earth Planet Sci 2:32. doi:10.1186/ s40645-015-0061-6

Horikawa K, Kodaira T, Zhang J, Murayama M (2015) $\delta^{18}$ Osw estimate for Globigerinoides ruber from core-top sediments in the East China Sea. Prog Earth Planet Sci 2:19. doi:10.1186/s40645-015-0048-3

Ikehara K (2015) Marine tephra in the Japan Sea sediments as a tool for paleoceanography and paleoclimatology. Prog Earth Planet Sci 2:36. doi:10. 1186/s40645-015-0068-z

Itaki T (2016) Transitional changes in microfossil assemblages in the Japan Sea from the Late Pliocene to Early Pleistocene related to global climatic and local tectonic events. Prog Earth Planet Sci 3:11. doi:10.1186/s40645-016-0087-4

Kim RA, Lee KY, Bae SW (2015) Sea surface temperature proxies (alkenones, foraminiferal $\mathrm{Mg} / \mathrm{Ca}$, and planktonic foraminiferal assemblage) and their implications in the Okinawa Trough. Prog Earth Planet Sci 2:43. doi:10.1186/ s40645-015-0074-1 
Kubota Y, Kimoto K, Tada R, Oda H, Yokoyama Y, Matsuzaki H (2010) Variations of East Asian summer monsoon since the last deglaciation based on $\mathrm{Mg} / \mathrm{Ca}$ and oxygen isotope of planktic foraminifera in the northern East China Sea. Paleoceanography 25(4):PA4205. doi:10.1029/2009pa001891

Scudder RP, Murray RW, Schindlbeck JC, Kutterolf S, Hauff F, Underwood MB, Gwizd S, Lauzon R, McKinley CC (2016) Geochemical approaches to the quantification of dispersed volcanic ash in marine sediment. Prog Earth Planet Sci 3:1. doi:10.1186/s40645-015-0077-y

Suzuki Y, Tada R, Yamada K, Irino T, Nagashima K, Nakagawa T, Omori T (2016) Mass accumulation rate of detrital materials in Lake Suigetsu as a potential proxy for heavy precipitation: a comparison of the observational precipitation and sedimentary record. Prog Earth Planet Sci 3:5. doi:10.1186/ s40645-016-0081-x

Tada R, Irino T, Koizumi I (1999) Land-ocean linkages over orbital and millennial timescales recorded in late Quaternary sediments of the Japan Sea. Paleoceanography 14:236-247

Tada R, Zheng H, Clift P (2016) Evolution and variability of the Asian monsoon and its potential linkage with uplift of the Himalaya and Tibetan Plateau. Prog Earth Planet Sci 3:4. doi:10.1186/s40645-016-0080-y

\section{Submit your manuscript to a SpringerOpen ${ }^{\odot}$ journal and benefit from:}

- Convenient online submission

- Rigorous peer review

- Immediate publication on acceptance

- Open access: articles freely available online

- High visibility within the field

- Retaining the copyright to your article

Submit your next manuscript at $\boldsymbol{s p r i n g e r o p e n . c o m ~}$ 